Historic, Archive Document

Do not assume content reflects current scientific knowledge, policies, or practices. 



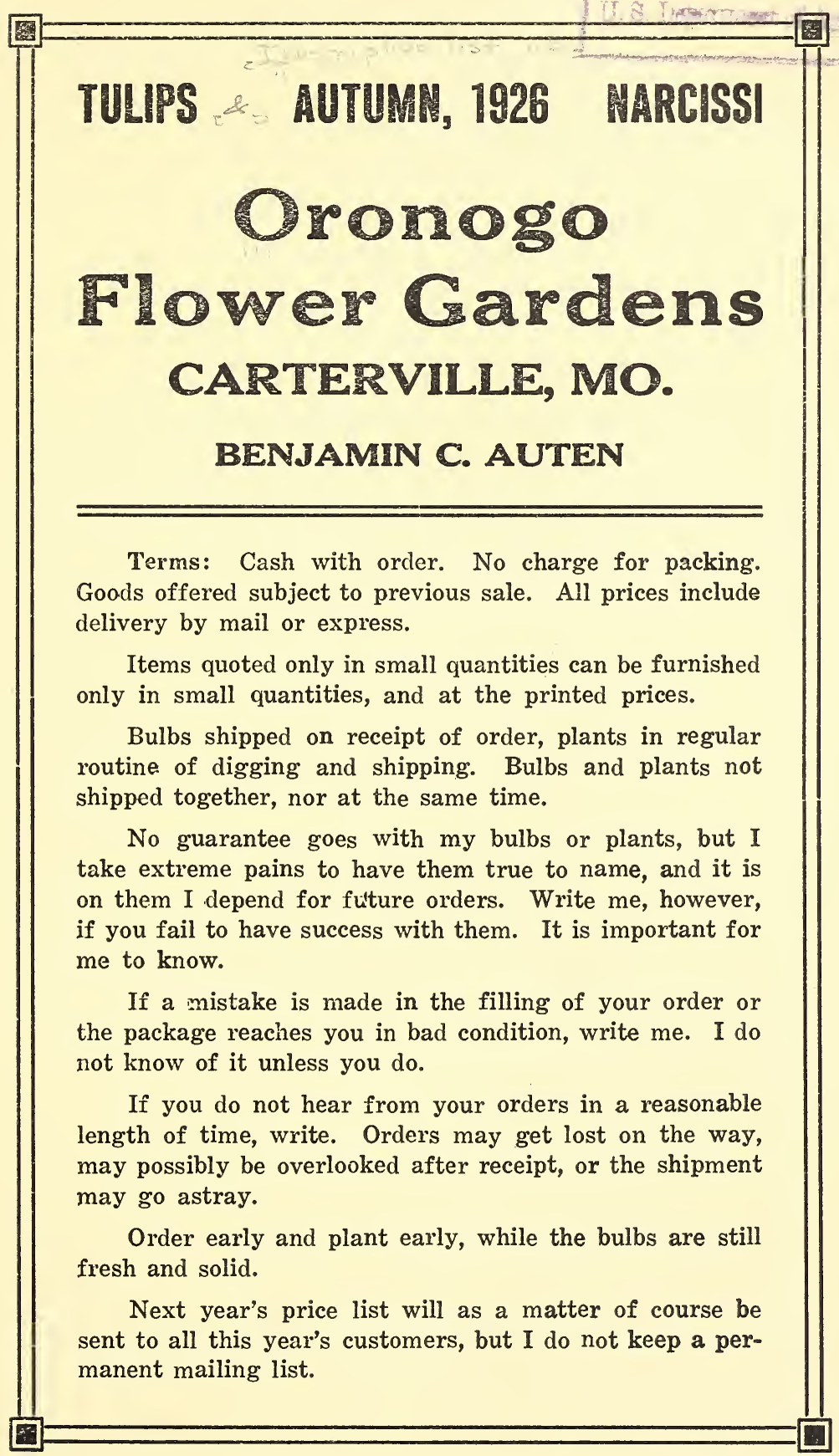


As my customers mostly are familiar with the management of these flowers, I am omitting this year the usual detailed information and planting directions. I have a number of old left-over catalogues, however, which give full information, and shall gladly send a copy to anyone wishing it. A postal-card request will bring one.

Tulip and narcissus bulbs should be planted about three inches deep to the tops of the bulbs as soon as possible after summer heat and drouth are broken, must remain in the ground over winter, and should not be disturbed until the leaves have turned yellow in early summer. This is the correct time to dig them. Narcissi prefer to be left in the ground several years. Tulips are better dug every year, though they may be let go an extra year if small when planted.

Bulbs should not be allowed to lic in the sun when dug, nor when planting, nor at any other time. They should be stored cool, dark, and well ventilated.

\section{NARCISSUS BULBS}

My descriptions may seem shcrt, but there is a large amount of description in the key following the name. The Ajax type is the one with the long trumpet; the Incomparabilis has the half-length trumpet or cup, the Barrii the quarter-length cup. The Poeticus type has a white flower with a little flat red-edged saucer in the center. The Poetaz, Tazetta, and Jonquil types are bunch flowered and the blooms have small cups. The Leedsii type has medium or small cups and is primrose-white in color. $\mathrm{Y}$, W, and Bic stand respectively for yellow, white and bi-color (white with yellow trumpet or cup). 1, 2, -6 tells the season of bloom. F means that a variety is good for foreing, FF that it is very good.

My supply of many of these varieties is very small: threfore do not order more of any kind than the largest number offered of that kind.

Mixture A. A collection of standard varieties from an old yard-planting, consisting of severai types, and inciuding a good proportion of yellows. 12 for 70 c, 100 for $\$ 5.00,250$ for $\$ 11.25,1,000$ for $\$ 42.50$.

Mixture B. This is the same collection, but, the bulbs being graded smaller, there will be a larger proportion of white varieties. 12 for $50 \mathrm{c}$, 100 for $\$ 3.00,250$ for $\$ 6.75,1,000$ for $\$ 25.00$.

Mixture C. The same collection, but bulbs under blooming size. 100 for $\$ 1.20,250$ for $\$ 2.75,1,000$ for $\$ 10.00$.

Albatross. BarW5F. A large flat flower, and a robust variety. 11c. 3 for $30 c, 10$ for $90 c$.

Ariadne. LdW3F. A fine flower. Trumpet ivory-white, very broad and spreading. 10c. 3 for $27 \mathrm{c}, 10$ for $80 \mathrm{c}, 100$ for $\$ 7.00$.

Blood Orange. BarBic5. A star-shaped creamy-white flower with very brilliant orange-red cup. A charming flower. 11c. 3 for $30 \mathrm{c}, 10$ for $90 \mathrm{c}$.

Cardinal. IncY3. Very fine. The cup is medium in size, and bright red. 12c. 3 for $33 c$.

Chaucer. PtW3F. The earliest of the poeticus varieties, and one of the most charming. The eye is very small and very brilliant. $10 \mathrm{c}$. 3 for $27 \mathrm{c}, 10$ for $80 \mathrm{c}, 25$ for $\$ 1.85$.

Conspicuus. BarY4F. One of the old dependables. The short cup is rimmed rich red. 9c. 3 for $24 c, 10$ for $70 \mathrm{c}, 100$ for $\$ 6.00,250$ for $\$ 13.50$.

Double Poeticus. PtW6. A beautiful flower, coming right for Mother's Day in some localities. 9c. 3 for $24 \mathrm{c}, 10$ for $70 \mathrm{c}, 50$ for $\$ 3.00$.

Elvira. PzW3F. 9c. 


\section{BENJAMIN C. AUTEN}

Oronogo Flower Gardens

CARTERVILLE, MO.

Amount Enclosed $\$$

Date

Name

Street or R.F. D. No.

Post Office

State

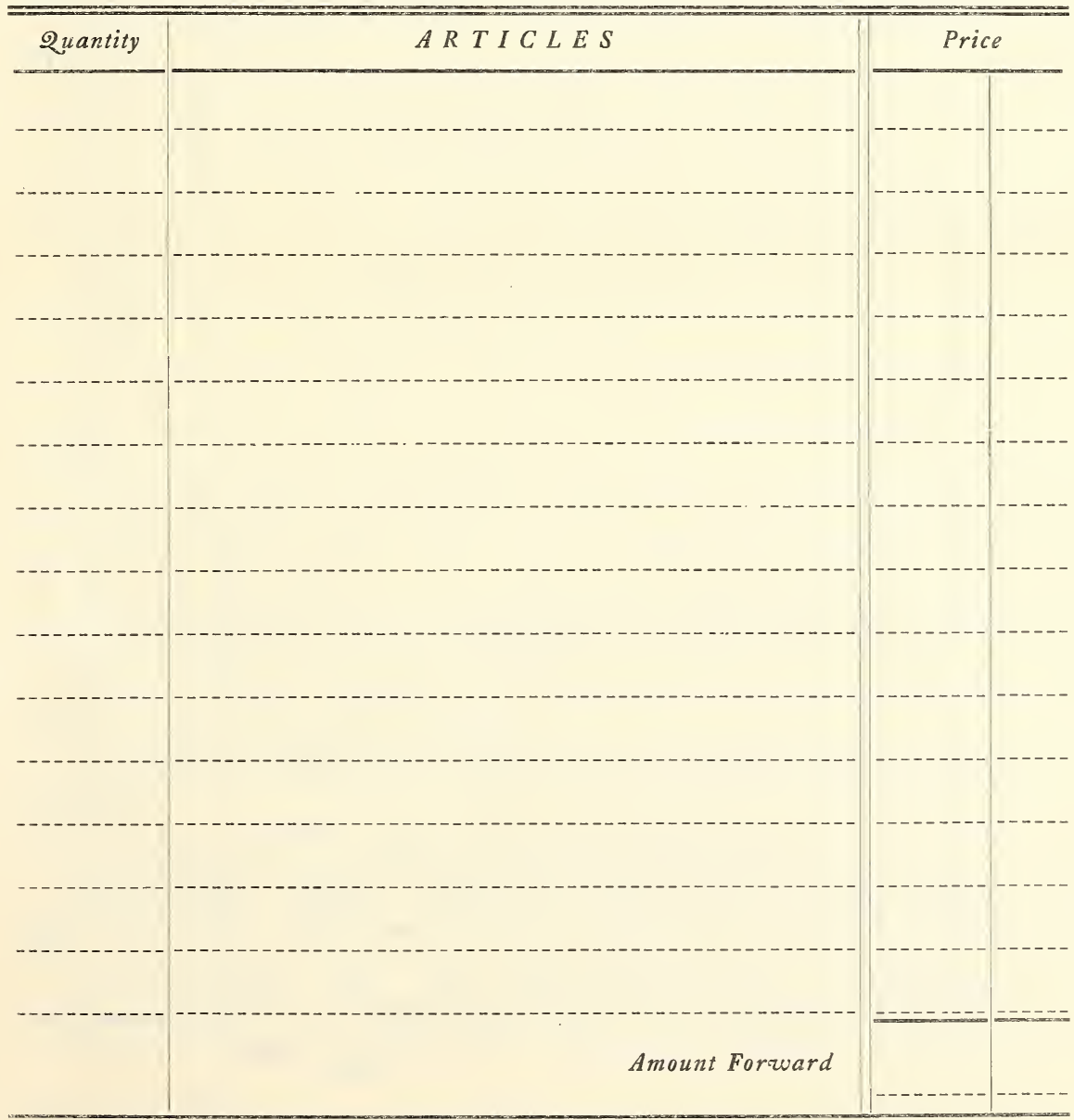




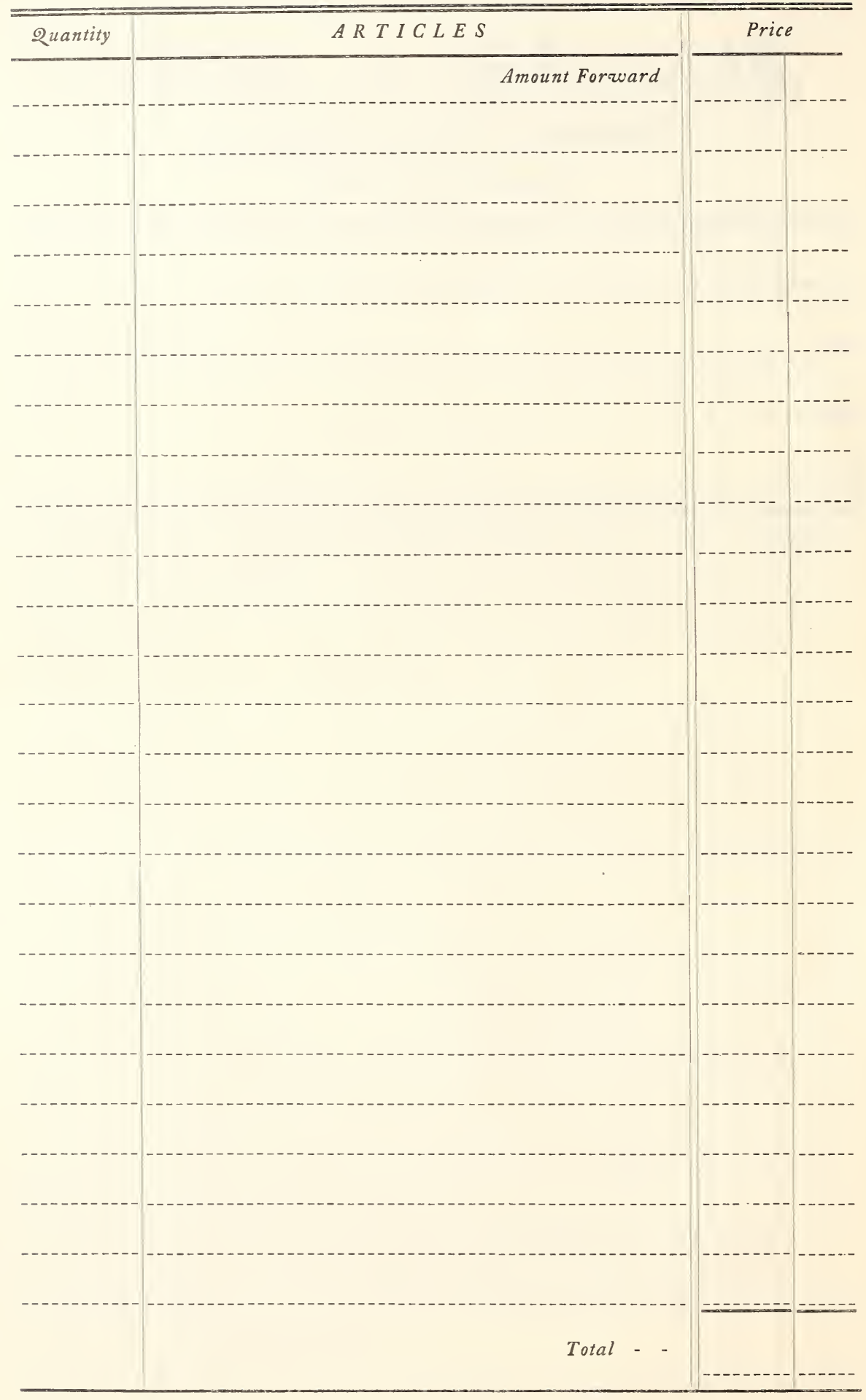


Emperor. AjY3F. The popular large yellow narcissus. 12c. Only 1 to a customer.

Fairy Queen. LdW2F. A high-grade flower, all white. 10c. 3 for 27c, 10 for $80 \mathrm{c}$.

Glory. ..PtW4. Large, and of snowy whiteness. 9c. 3 for 24c, 10 for 70 c, 100 for $\$ 6.00$.

Grandiflorus PtW5F. The most striking in size and form of all the poeticlis varieties. Its slightly greenish tinge, with its crepe-like texture, makes it also the most brilliant at a little distance. 9c. 3 for 24c, 10 for 70 c, 100 for $\$ 6.00,250$ for $\$ 13.50$.

Horace. PtW5. One of the largest and finest of the poeticus variaties. The eye is deep red nearly to the center. 13c. 3 for $36 \mathrm{c}, 10$ for $^{\circ}$ $\$ 1.10,25$ for $\$ 2.50$.

Hyacinth. BarW6. Snowy petals, small yellow cuip. 8c. 3 for 21c, 10 for $60 \mathrm{c}$.

Ivemia. IncBic6. Brilliant white, with short straight cup of clearest yellow. Very late. 10c. 3 for 27c.

Katherine Spurrell. LdW4F. Primrose-white in color, unique in form. 10c. 3 for $27 \mathrm{c}$.

King Edward. PtW5FF. The best forcer of the poeticus varicties and a brilliant flower. 9c. 3 for $24 \mathrm{c}, 10$ for $70 \mathrm{c}$.

Lady Bird. IncY2F. The earliest red-cupped narcisslis I know. 10c. 3 for 27c.

Lady Godiva. BarBic4. Like Conspicuus, except that the petals are white. 9c.

Laureate. PtW4. Another choice poeticus narcissus. 10c.

Maggie May. LdW2. Shape of Sir Watkin, smaller, and white. 12c. 3 for 33c.

Minister Talma. AjY2F. A very early and large yellow trumpet narcissus. 11c.

Mrs. Thompson. AjW2. A very early white trumpet narcissus. 9c. 3 for $24 \mathrm{c}$.

Obvallaris. AjY1F. Deep golden, very early, very characteristic in form. 10c. 3 for $27 \mathrm{c}, 10$ for $80 \mathrm{c}$.

Orange Cup (?). AjY1. Deep yellow. Trumpet very broad and very flaring. 10c. 3 for 27c.

Pheasant Eye. PtW6. The common late poeticus narcissus. This stock may be slightly mixed with the double variety, but I do not hold myself responsible for it. 7c. 3 for $18 \mathrm{c}$.

Sequin. BarBic4. Cup deep golden yellow, flattened back against the petals of pure white. 10c. 3 for $27 \mathrm{c}$.

Sir Watkin. IncY2FF. The largest early incomparabilis narcissus, and one of the most desirable of all narcissi. 11c. 3 for $30 \mathrm{c}, 10$ for $90 \mathrm{c}, 100$ for $\$ 8.00$.

Victoria. AjBic2FF. One of the most beautiful of the large bicolor trumpet narcissi. 11c. 3 for $30 \mathrm{c}, 10$ for $90 \mathrm{c}, 25$ for $\$ 2.00$.

White Lady. LdW4F. A large flat white flower of crepe texture. Cup small, heavily crinkled, citron-yellow in color. 10c. 3 for $27 \mathrm{c}, 10$ for $80 \mathrm{c}$.

White Standard. PtW4. Has almond-shaped petals. Is similar but much superior to the old Poeticus Poetarum. 9c. 3 for $24 \mathrm{c}, 10$ for $70 \mathrm{c}$.

William Goldring. AjW1F. The "Dog-eared Daffodil." An easy 
forcer, and especially beautiful when forced. 9 c. 3 for 24 c, 10 for 70 c, 25 for $\$ 1.60$.

Will Searlet. IncBic5. Has a large flaring cup of rich red. A variety unique. 25c. Only 1 to a customer.

N. B. All prices include delivery by mail or express.

\section{TULIP BULBS}

Mixed Late. All colors and several types, including a few Breeders and some Darwins. 12 for $40 \mathrm{c}, 25$ for $70 \mathrm{c}, 100$ for $\$ 2.40,250$ for $\$ 5.40$.

Pouton d'Or. Rich golden yellow, with black anthers. 6c.

Columbus. Sharply pointed, striped red and orange. 7c. 3 for 18c.

Filen Filmott. Tall slender bud, pale cream in color, very late, very fragrant. 6c. 3 for 15c, 12 for $54 c, 25$ for $90 c, 100$ for $\$ 3.20$.

Inglescombe Yellow. Cup-shaped flower of purest sulphur-yellow. Very late. 6 c. 3 for 15 c, 12 for $48 c, 25$ for 90 c, 100 for $\$ 3.00$.

Mrirs. Noon. Pure clear yellow. Tall stem, pointed flower. 6c. 3 for $15 \mathrm{c}, 12$ for $54 \mathrm{c}, 25$ for $90 \mathrm{c}, 100$ for $\$ 3.20$.

Striped Parrot. The parrot tulips have long petals with ragged edges, and are the showiest of all tulips. This variety and the next are the finest of the parrots. If you wish something gaudy, this is it. $6 \mathrm{c} .3$ for $15 \mathrm{c}, 12$ for $48 \mathrm{c}, 25$ for $90 \mathrm{c}, 100$ for $\$ 3.00$.

Yellow Parrot. Pure clear yellow. The brightest of the parrots. 6c. 3 for 15 s, 12 for $48 c$, 25 for 90 c, 100 for $\$ 3.00$.

\section{DARWIN TYPE}

In refined beauty there is mothing else in tulips to equal the Darwins, except that the pure yellows of the Cottage type share honors with them.

Mixed Darwins. This mixture is not made up of the varieties listed below, though some of them will be found in it, but there is a full range of colors in great variety. 12 for $48 \mathrm{c}, 25$ for $90 \mathrm{c}, 100$ for $\$ 3.00$.

"c." Name unknown. White, exquisitely tinted porcelain-blue. 6c. 3 for $14 \mathrm{c}, 12$ for $44 \mathrm{c}, 25$ for $80 \mathrm{c}, 100$ for $\$ 2.80$.

City of Haarlem (?). Glowing scarlet-red, with black center outlined in ivory-white. The most gorgeouts flower in the garden. 10c. 3 for 24c, 12 for $78 c$.

Clara Butt. Apricot-pink, an exquisite color. The first favorite of all tulips, and a fine market flower. 6c. 3 for $15 \mathrm{c}, 12$ for $48 \mathrm{c}, 25$ for $90 \mathrm{c}, 100$ for $\$ 3.00,250$ for $\$ 6.60,1,000$ for $\$ 24.00$. $36 c$.

"d." Name unknown. A fine large purple tulip. 8c. 3 for 20c, 6 for

Edmee. One of the finest and tallest of deep pink tulips. 7c. 3 for $17 \mathrm{c}, 12$ for $54 \mathrm{c}, 25$ for $\$ 1.00$.

Farncombe Sanders. The loveliest of the red tulips. A fine market flower. 7c. 3 for 17 c, 12 for 54 c, 25 for $\$ 1.00,100$ for $\$ 3.60,250$ for $\$ 8.00$.

F. Sanders, Rembrandt. Same as Farncombe Sanders, but splashed with pure white. 7c. 3 for $17 \mathrm{c}, 6$ for $30 \mathrm{c}$.

Glory of Walworth. A fine purple variety. $8 \mathrm{c}$.

Gudin. Deep lilac shaded to white, a somber color such as is found in no other flower. $6 c$. 3 for $14 \mathrm{c}, 12$ for $44 \mathrm{c}$.

Kate Greenaway. White, slightly flushed lilac-rose. Lasts the longest in bloom of any. 6c. 3 for $15 \mathrm{c}, 12$ for $48 \mathrm{c}$.

La Fiancee. Very large flower, lilac-rose. A recent introduction. 10c. 3 for $25 c$. 
La Tristesse. Dull slaty blue. One of the finest of blue tulips. 6c. 3 for $15 \mathrm{c}, 12$ for $54 \mathrm{c}, 25$ for $90 \mathrm{c}$.

for $18 \mathrm{c}$.

Marconi. A fine dark variety. Maroon, with yellow center. 7c. 3

Mattia. Very fine red. 7c. 3 for $18 \mathrm{c}$.

Melicette. Lilac. A superb variety. 7c. 3 for $18 \mathrm{c}$.

Meteor. A fine red variety. 8c. 3 for $20 \mathrm{c}$.

Mrs. Cleveland. Delicate flesh-pink in color, and exquisite in form. 6c. 3 for 15 c, 12 for $54 c, 25$ for 90 c, 100 for $\$ 3.00$.

Mystery. The biggest and blackest of the black tulips. 16c. 3 for 40c.

Opal. Heliotrope-lilac. A very brilliant dark-colored tulip, with exquisitely beautiful bud. 8c. 3 for 20 c, 12 for 66 c, 25 for $\$ 1.20,100$ for $\$ 4.40$.

Painted Lady. Heliotrope-white, color of exquisite softness. 6c. 3 for $15 \mathrm{c}, 12$ for $48 \mathrm{c}, 25$ for $90 \mathrm{c}$.

Rev. Ewbank. Beautiful heliotrope. One of the most brilliant of the blues. 6c. 3 for $15 \mathrm{c}, 12$ for $54 \mathrm{c}$.

Rev. Wolley Dod. Very dark blue. Very late. 7c. 3 for 18c.

Sir Harry Veitch. Rich dark red. Very large flower. 8c. 3 for 20c.

Sophrosyne. Soft rosy lilac. A very sombre flower and very beautifull. $7 \mathrm{c}$. 3 for $18 \mathrm{c}, 12$ for $60 \mathrm{c}$.

White Queen... Cream-white, flushed pink. 6c. 3 for 15c.

Planting Stock. If you wish to grow tulips in quantity for the sale of bulbs or flowers, send for the wholesale list of small-size planting stock.

\section{MISCELLANEOUS}

Snowdrop. Galanthus Nivalis. 5c. 6 for 20 c, 12 for 36 c.

Star of Bethlehem. Ornithogalum Umbellatum. 5c. 6 for 20c, 25 for 50 c, 250 for $\$ 4.00$.

Grape Hyacinth. Mammoth bulbs. 10c.

Hyacinths. Furnished only in mixed colors in mixed sizes. Only 25c worth to a customer, as my supply is small.

Lilium Candidum. Madonna lily. Pure white. 30c if ordered with other bulbs, otherwise $40 \mathrm{c}$. Only 1 to a customer.

N. B. All prices in this list include delivery by mail or express.

Please do not write letters on your order sheet, nor write orders in your letters. Have the letter and the order on separate sheets. Also it will be a help if you will write your bulb order and your plant order on separate sheets.

If you are a flower lover, you want and will appreciate a flower magazine. The Flower Grower, Calcium, N. Y. Subscription price for one year is $\$ 2.00$, for 3 years is $\$ 4.50$, for 5 years is $\$ 6.00$.

If you are an iris enthusiast, you need and will appreciate the book by $\mathrm{Mr}$. Walter Stager, The Bearded Iris, price $\$ 2.00$, published by The Flower Grower, Calcium, N. Y. Orders for the magazine and the book can be sent to me or direct to the publisher, at your convenience.

I do not issue a spring list, but irises, eulalias, bamboo, snowdrops and star of Bethlehem can be ordered in the spring from my fall lists. Peonies, tulips, and narcissi I do not furnish in the spring.

The statement in my peony and iris list that shipments would begin about September 1 was intended to apply to the peony only. Orders for irises I shall be glad to fill at any time. 

